\title{
Antibiotic Resistance Pattern of Uropathogens in a Tertiary Care Hospital in Calabar, Nigeria
}

\author{
Bassey Ewa Ekeng ${ }^{1^{*}}$, Ernest Afu Ochang ${ }^{2}$, David Ewuru Elem ${ }^{3}$, \\ Promise Akugom Owai ${ }^{1}$, Bernard Ekpan Monjol ${ }^{1}$, \\ Ikechukwu Henry Ukweh ${ }^{4}$, Chimaobi Ikechukwu Nwagboso ${ }^{5}$, \\ Bode Akashie Abraka ${ }^{1}$ and Simon Edward Ereh ${ }^{6}$
}

\footnotetext{
${ }^{1}$ Department of Medical Microbiology and Parasitology, University of Calabar Teaching Hospital, Calabar, Nigeria.

${ }^{2}$ Department of Medical Microbiology and Parasitology, University of Calabar / University of Calabar Teaching Hospital, Calabar, Nigeria.

${ }^{3}$ Department of Internal Medicine, University of Calabar Teaching Hospital, Calabar, Nigeria. ${ }^{4}$ Department of Community Medicine, University of Calabar Teaching Hospital, Calabar, Nigeria. ${ }^{5}$ Department of Surgery, Division of Cardiothoracic and Vascular Surgery, University of Calabar 1 University of Calabar Teaching Hospital, Calabar, Cross River State, Nigeria.

${ }^{6}$ Department of Internal Medicine, Infectious Disease Unit, University of Calabar Teaching Hospital, Calabar, Nigeria.
}

\section{Authors' contributions}

This work was carried out in collaboration among all authors. Authors BEE and EAO were involved in the conception and design of the study. Author BEE drafted the initial manuscript. Authors BEE, DE, $P O, B E M$ and $B A A$ were involved in laboratory work and wrote manuscript. Authors EAO, IU, CN and SEE conducted a critical review of the manuscript. All authors have read and approved the final manuscript.

\section{Article Information}

DOI: $10.9734 / A R R B / 2021 / v 36 i 630385$

Editor(s):

(1) Dr. Gunanidhi Dhangadamajhi, North Orissa University, India. Reviewers:

(1) Harit Kumar, Maharishi Markandeshwar Institute of Medical Science and Research, India. (2) Bikash Bikram Thapa, Nepalese Army Institute of Health Sciences, Nepal. Complete Peer review History: http://www.sdiarticle4.com/review-history/69255

Original Research Article

Received 28 March 2021

Accepted 07 June 2021

Published 15 June 2021

\section{ABSTRACT}

Introduction: Urinary tract infection is a major reason for hospital visits and a common clinical condition encountered by clinicians. The causative agents of urinary tract infection and their resistant pattern vary globally. The aim of this study was to highlight the profile of pathogens 
associated with urinary tract infections in our locality. The objective was to investigate the resistant pattern of these microbial isolates from patients with urinary tract infection and offer recommendations for effective treatment.

Materials and methods: We retrospectively analyzed the urine culture and antimicrobial sensitivity reports of patients with suspected urinary tract infection at the University of Calabar Teaching Hospital, Calabar, Nigeria, from September 2019 to August 2020. Methicillin resistance was detected by disk diffusion method using $30 \mu \mathrm{g}$ cefoxitin disk. Production of Extended spectrum beta lactamases was detected by the Combination disk and the double-disk synergy method.

Results: Of 979 urine culture and sensitivity reports, $306(31.26 \%)$ were positive for microbial growth. Two microbial isolates each were recovered from urine samples of 5 patients giving a total number of 311 isolates from 306 patients. $45.75 \%$ of positive results were in males. The predominant isolate was Escherichia coli $(\mathrm{n}=97,31.19 \%)$. Extended Spectrum Beta Lactamases (ESBL) producing strains comprised $10.08 \%$ (10/238) of Gram-negative group of organisms, while $47.39 \%(145 / 306)$ of all bacterial isolates in our study were multi drug resistant (MDR). $14.29 \%$ $(6 / 42)$ of $S$. aureus isolates were methicillin resistant $S$. aureus, while $33.33 \%(2 / 6)$ of methicillin resistant $S$. aureus (MRSA) were multi drug resistant.

Conclusion: Urinary tract infection caused by antimicrobial resistant organisms is common among studied patients. This emphasizes the need for urine culture and sensitivity tests in the management of urinary tract infection.

Keywords: Antibiotic; resistance; susceptibility; infection; uropathogens.

\section{INTRODUCTION}

Urinary tract infections (UTI) are defined by the presence of a growth of more than $10^{5}$ colony forming units (CFU) of bacteria per $\mathrm{ml}$ of urine for asymptomatic individual and $\sim 10^{3} \mathrm{CFU} / \mathrm{ml}$ for symptomatic individual $[1,2]$. In urine samples obtained by supra pubic aspiration or catheterization and in samples from a patient with an indwelling catheter, colony count of $10^{2}$ $10^{4} \mathrm{CFU} / \mathrm{ml}$ generally signifies urinary tract infection [1]. UTI are one of the commonest clinical conditions encountered by physicians and accounts for $1-6 \%$ of all medical visits [3]. It is the second most common reason for empirical antibiotic treatment and a major reason for antibiotic usage globally [4]. Therefore, the need for periodic monitoring of causative agents in a given locality and their resistance pattern is necessary to ensure appropriate and successful treatment.

\section{MATERIALS AND METHODS}

This is a retrospective study, conducted at University of Calabar Teaching Hospital Calabar, Nigeria. Study population comprised patients aged between 1 and 88 years who attended the hospital with complaints of UTI symptoms. A total of 979 urine culture reports were analyzed. Urine specimens were inoculated on Blood agar and McConkey agar plates or Cysteine lactose electrolyte deficient agar plates (Himedia) using $2 \mathrm{~mm}$ calibrated loops $(0.002 \mathrm{ml})$ and were incubated aerobically at $37^{\circ} \mathrm{C}$ for $24-48$ hours. Culture plates showing growth of $>20$ colonies $\left(>10^{5} \mathrm{CFU} / \mathrm{ml}\right)$ colonies were considered as Significant bacteriuria and were subjected to standard biochemical tests (Catalase, Coagulase, Indole, Citrate, Urea and Kligler iron agar) for identification of isolates. Besides conventional biochemical tests, Oxoid Microbact TM GNB kit and Analytical profile index 20E were also used for the identification of culture isolates $[5,6]$. Antimicrobial sensitivity testing was done using the Kirby- Bauer disc diffusion method. Interpretation of results as 'Sensitive' or 'Resistant' or 'Intermediate' was done according to the Clinical and Laboratory Standard Institute (CLSI) guidelines [7]. Antibiotics against which sensitivity was tested in this study included ampicillin, amoxiclav, amikacin, cefoxitin, ceftriaxone, cefuroxime, ceftazidime, cefepime, cefixime, cefotaxime, ciprofloxacin, imipenem, meropenem, levofloxacin, piperacillin/tazobactam, gentamicin and nitrofurantoin. Quality control as per CLSI standards was done for antimicrobial susceptibility tests to confirm the potency of antibiotics [7]. Detection of ESBL production in Gram negative bacteria was done as per CLSI guidelines, by Phenotypic Confirmatory Disc Diffusion Test (PCDDT) and/or the Double Disc Synergy Test (DDST). A zone diameter of more than $5 \mathrm{~mm}$ for Ceftazidimeclavulanate $(30 / 10 \mathrm{mcg})$ compared to ceftazidime (30 mcg) was considered positive for ESBL (PCDDT). DDST was done using a combination of antibiotics including Aztreonam 
(30mcg), Amoxicillin-Clavulanic acid $(20 / 10 \mathrm{mcg})$, Ceftriaxone $(30 \mathrm{mcg})$, Ceftazidime $(30 \mathrm{mcg})$ and Cefotaxime $(30 \mathrm{mcg})$. The development of zone of inhibition towards the Clavulanate disc was indicative of a potential ESBL positive organism $[6,7]$. Detection of methicillin resistance was done as per CLSI guidelines [7].

\section{RESULTS}

A total of 979 urine culture sensitivity reports were analyzed retrospectively out of which 306 were positive for microbial growth. Two microbial isolates each were recovered from urine samples of 5 patients giving a total number of 311 isolates from 306 patients. Among the 306 reports, 166 $(54.25 \%)$ belonged to females. The age range was 1 to 88years with a mean of 36.4 years. Table 1 summarizes the age distribution of patients and the number of cultured isolates per age group. The predominant culture isolates in our study were; $E$. coli $(\mathrm{n}=97,31.2 \%)$ and Staphylococcus aureus $(\mathrm{n}=36,11.58 \%)$. Gramnegative bacilli were a total of $238(77.78 \%)$ and accounted for most of the culture isolates. Gram positive cocci were a total of $68(21.86 \%)$, while $5(1.61 \%)$ culture reports were positive for Candida spp. as shown in Table 2.

\section{DISCUSSION}

The sex distribution of patients in our study is consistent with studies previously done in many centers with a higher prevalence of UTI in females $(54.23 \%)$ compared to males [8]. The high prevalence of UTI in females compared to males is related to the anatomical and microflora differences between the male and female genitourinary systems $[1,9]$. Women are more susceptible than men because of short straight anatomy of the urethra and termination of female urethra beneath the labia resulting in colonization of the urinary tract by colonic Gram-negative bacilli. Pregnancy also increases the risk of UTI in females due to positional changes within the urinary tract caused by the enlarged uterus. Associated hormonal changes in pregnancy also causes susceptibility to urinary tract infections in pregnant women. Other factors include decreased ureteric tone and peristalsis, temporary incompetence of the vesicoureteral valves and bladder catheterization $[9,10]$. Social activities in females like sexual activity, douching and child birth also increase the risk of urethral contamination as the bacteria could be pushed into the urethra during sexual intercourse as well as bacteria being massaged up the urethra into the bladder during child birth $[9,10]$.

The incidence rate $(31.26 \%)$ of UTI in our study was much higher compared to a previous study $(7.7 \%)$ from the same center carried out by Jumbo et. al, 2011 [8]. Both studies were retrospective in nature, but of varied duration. Our study spanned a duration of one year while the previous study covered a duration of five years [8]. The higher incidence from our study despite the short duration may be attributed to improved infrastructure and laboratory services, increased skilled man power, a better working environment and the drive to attain international best practices.

The predominant isolate in our study was $E$. coli. Its prevalence $(37.19 \%)$ in this study was similar to other reports [11,12]. Globally, more than $80 \%$ of UTI are caused by uropathogenic Escherichia coli and Klebsiella species specifically, $K$. pneumoniae and $K$. oxytoca, both in the community and nosocomial settings $[13,14]$. $E$. coli is the etiological agent in $60-90 \%$ of UTI, while Klebsiella species accounts for $3-20 \%$ of cases [13,14].

Age group 16-44 years had the highest frequency of UTI $(61.74 \%)$ probably due to increased sexual activity as corroborated from other studies (Table 1) $[8,12]$. The commonest etiological agents causing UTI in the younger age group (1-15) were $E$. coli $(\mathrm{n}=3), \quad P$. aeruginosa $(\mathrm{n}=2)$, Acinetobacter spp. $(\mathrm{n}=2)$, and Enterococcus spp. $(\mathrm{n}=2)$. Amongst the elderly $(\geq 65)$, the predominant isolates were; $E$. coli $(\mathrm{n}=18)$, Morganella morganii $(\mathrm{n}=7)$, and Staphylococcus spp. ( $\mathrm{n}=5)$. Within age groups 16-44 and 45-64, all culture isolates were implicated except for Acinetobacter spp. which were not implicated as causative agents of UTI for age group 45-64. This may be explained by the varied distribution of uropathogens across age groups as documented in previous studies $[15,16]$.

Analysis of antimicrobial susceptibility results of culture isolates revealed high resistance to antibiotics (ciprofloxacin, levofloxacin and ceftriaxone) commonly used for the empirical treatment of UTI. Klebsiella spp. were highly resistant to ceftriaxone $(70 \%)$, ceftazidime $(63 \%)$, gentamicin (63\%), ciprofloxacin $(57 \%)$ and amoxicillin-clavulanic acid (66\%). This finding was in keeping with previous studies [17]. Klebsiella spp. produce various enzymes including extended spectrum beta lactamases, 
metallo-beta-lactamases, oxacillinases, and carbapenemases that target beta lactam antibiotics. These enzymes are encoded on plasmids and are usually taken up by the process of conjugation $[1,18]$. Enterobacter spp. showed high resistant to ceftriaxone $(67 \%)$, cefuroxime $(62.5 \%)$ and cefdinir (62.5\%). Enterobacter spp. ESBLs and carbapenemases, including VIM, OXA, metallo- $\beta$-lactamase- 1 and Klebsiella pneumoniae carbapenemases [18]. Additionally, they cause opportunistic infections in immunocompromised patients and are also associated with nosocomial infections [18]. The highest resistance to antibiotics in our study was seen in Acinetobacter spp. especially to ceftriaxone (75\%). Antibiotic resistance in Acinetobacter. spp. is also mediated by carbapenemases including imipenem metallo $\beta$ - lactamases, encoded by blalMP, and oxacillinase serine $\beta$ lactamases, encoded by blaOXA [1618]. The lowest observed resistance was against imipenem; $4.12 \%, 7 \%$ and $12 \%$, for E. coli, Klebsiella spp. and Enterobacter spp. respectively. A similar finding was reported in a previous study done by Iregbu et. al in a tertiary hospital, Abuja, Nigeria [12]. The total prevalence of Gram-positive organisms in our study was $21.86 \%$, slightly higher than reports from previous studies [8]. This is consistent with the fact that there's been a surge in Staphylococcus aureus associated UTI attributed to increased instrumentation like bladder catheterization and receptive anal intercourse [19-21]. Tables 3 and 4 summarized the resistance rates of Gram positive and Gram-negative isolates to tested antibiotics.

Table 1. Age distribution of cases of UTI

\begin{tabular}{lll}
\hline Age group (years) & Number of isolates & Percentages \\
\hline $1-15$ & 12 & 3.86 \\
$16-44$ & 192 & 61.74 \\
$45-64$ & 63 & 20.26 \\
$\geq 65$ & 44 & 14.15 \\
Total & 311 & 100 \\
\hline
\end{tabular}

Table 2. Frequency of culture isolates

\begin{tabular}{lll}
\hline Isolates & Number of Isolates & Percentage \\
\hline Escherichia coli & 97 & 31.19 \\
Staphylococcus aureus & 36 & 11.58 \\
Enterococcus spp. & 23 & 7.40 \\
Morganella morganii & 19 & 6.11 \\
Providencia alcalifaciens & 19 & 6.11 \\
Klebsiella oxytoca & 18 & 5.79 \\
Proteus vulgaris & 15 & 4.82 \\
Providencia rettgeri & 11 & 3.54 \\
Pseudomonas aeruginosa & 11 & 3.54 \\
Klebsiella pneumoniae & 10 & 3.22 \\
Enterobacter cloacae & 10 & 3.22 \\
Proteus mirabilis & 9 & 2.89 \\
Providencia stuartii & 6 & 1.93 \\
MRSA & 6 & 1.93 \\
Citrobacter freundii & 5 & 1.61 \\
Candida spp. & 5 & 1.61 \\
CoNS & 3 & 0.96 \\
Acinetobacter iwoffi & 2 & 0.64 \\
Acinetobacter baumanii & 2 & 0.64 \\
Enterobacter agglomerans & 2 & 0.64 \\
Klebsiella ozaenae & 2 & 0.64 \\
Total & 311 & 100 \\
\hline
\end{tabular}


Ekeng et al.; ARRB, 36(6): 10-18, 2021; Article no.ARRB.69255

Table 3. Antibiotic resistance pattern of Gram-negative bacterial isolates

\begin{tabular}{|c|c|c|c|c|c|c|c|c|c|}
\hline Ant. & E. coli & $\begin{array}{l}\text { Providencia } \\
\text { spp. }\end{array}$ & K. spp & Proteus spp. & M. morganii & E. spp. & P. aeruginosa & C. freundii & A. spp. \\
\hline \multicolumn{10}{|c|}{$\%$ (n) } \\
\hline CRO & $\begin{array}{l}35.05 \\
(34)\end{array}$ & $\begin{array}{l}55.56 \\
(20)\end{array}$ & $\begin{array}{l}70 \\
(21)\end{array}$ & $\begin{array}{l}29.12 \\
(7)\end{array}$ & $\begin{array}{l}40 \\
(8)\end{array}$ & $\begin{array}{l}67 \\
(8)\end{array}$ & $\begin{array}{l}45.5 \\
(5)\end{array}$ & $\begin{array}{l}20 \\
(1)\end{array}$ & $\begin{array}{l}75 \\
(3)\end{array}$ \\
\hline CXM & $\begin{array}{l}27.84 \\
(27)\end{array}$ & $\begin{array}{l}30.56 \\
(11)\end{array}$ & $\begin{array}{l}47 \\
(14)\end{array}$ & $\begin{array}{l}29.12 \\
(7)\end{array}$ & $\begin{array}{l}30 \\
(6)\end{array}$ & $\begin{array}{l}50 \\
(4)\end{array}$ & NT & $\begin{array}{l}20 \\
(1)\end{array}$ & NT \\
\hline CTZ & $\begin{array}{l}24.74 \\
(24)\end{array}$ & $\begin{array}{l}22.22 \\
(8)\end{array}$ & $\begin{array}{l}63 \\
(19)\end{array}$ & $\begin{array}{l}29.12 \\
(7)\end{array}$ & $\begin{array}{l}10 \\
(2)\end{array}$ & $\begin{array}{l}62.5 \\
(5)\end{array}$ & $\begin{array}{l}27.3 \\
(3)\end{array}$ & $\begin{array}{l}20 \\
(1)\end{array}$ & $\begin{array}{l}50 \\
(2)\end{array}$ \\
\hline $\mathrm{CN}$ & $\begin{array}{l}24.74 \\
(24)\end{array}$ & $\begin{array}{l}11.11 \\
(4)\end{array}$ & $\begin{array}{l}63 \\
(19)\end{array}$ & $\begin{array}{l}16.67 \\
(4)\end{array}$ & $\begin{array}{l}10 \\
(2)\end{array}$ & $\begin{array}{l}37.5 \\
(3)\end{array}$ & $\begin{array}{l}18 \\
(2)\end{array}$ & $\begin{array}{l}20 \\
(1)\end{array}$ & $\begin{array}{l}50 \\
(2)\end{array}$ \\
\hline Ak & NT & NT & $\begin{array}{l}20 \\
(6)\end{array}$ & NT & NT & $\begin{array}{l}12.5 \\
(1)\end{array}$ & NT & NT & $\begin{array}{l}50 \\
(2)\end{array}$ \\
\hline LEV & $\begin{array}{l}24.74 \\
(24)\end{array}$ & $\begin{array}{l}16.67 \\
(6)\end{array}$ & $\begin{array}{l}50 \\
(15)\end{array}$ & $\begin{array}{l}29.12 \\
(7)\end{array}$ & NT & $\begin{array}{l}37.5 \\
(3)\end{array}$ & $\begin{array}{l}9.0 \\
(1)\end{array}$ & $\begin{array}{l}40 \\
(2)\end{array}$ & $\begin{array}{l}50 \\
(2)\end{array}$ \\
\hline CIP & $\begin{array}{l}26.80 \\
(26)\end{array}$ & $\begin{array}{l}2.78 \\
(1)\end{array}$ & $\begin{array}{l}57 \\
(17)\end{array}$ & $\begin{array}{l}12.5 \\
(3)\end{array}$ & NT & $\begin{array}{l}50 \\
(4)\end{array}$ & NT & $\begin{array}{l}40 \\
(2)\end{array}$ & $\begin{array}{l}50 \\
(2)\end{array}$ \\
\hline AMC & $\begin{array}{l}24.74 \\
(24)\end{array}$ & $\begin{array}{l}2.78 \\
(1)\end{array}$ & $\begin{array}{l}66 \\
(20)\end{array}$ & $\begin{array}{l}16.67 \\
(4)\end{array}$ & NT & $\begin{array}{l}37.5 \\
(3)\end{array}$ & NT & $\begin{array}{l}20 \\
(1)\end{array}$ & NT \\
\hline MEP & $\begin{array}{l}12.37 \\
(12)\end{array}$ & NT & $\begin{array}{l}43 \\
(13)\end{array}$ & NT & NT & $\begin{array}{l}12.5 \\
(1)\end{array}$ & $\begin{array}{l}18.1 \\
(2)\end{array}$ & NT & NT \\
\hline CFM & $\begin{array}{l}11.34 \\
(11)\end{array}$ & NT & $\begin{array}{l}40 \\
(12)\end{array}$ & NT & NT & $\begin{array}{l}12.5 \\
(1)\end{array}$ & NT & NT & $\begin{array}{l}50 \\
(2)\end{array}$ \\
\hline cox & NT & NT & $\begin{array}{l}30 \\
(9)\end{array}$ & NT & NT & $\begin{array}{l}12.5 \\
(1)\end{array}$ & NT & NT & $\begin{array}{l}50 \\
(2)\end{array}$ \\
\hline IMP & $\begin{array}{l}4.12 \\
(4)\end{array}$ & NT & $\begin{array}{l}7 \\
(2)\end{array}$ & NT & NT & $\begin{array}{l}12.5 \\
(1)\end{array}$ & NT & $\begin{array}{l}20 \\
(1)\end{array}$ & $\begin{array}{l}50 \\
(2)\end{array}$ \\
\hline CPD & $\begin{array}{l}7.21 \\
(7)\end{array}$ & NT & $\begin{array}{l}10 \\
(3)\end{array}$ & NT & NT & NT & NT & NT & NT \\
\hline AMP & $\begin{array}{l}16.49 \\
(16)\end{array}$ & NT & NT & NT & NT & $\begin{array}{l}12.5 \\
(1)\end{array}$ & NT & $\begin{array}{l}40 \\
(2)\end{array}$ & NT \\
\hline NIT & $\begin{array}{l}16.49 \\
(16)\end{array}$ & $\begin{array}{l}22.22 \\
(8)\end{array}$ & $\begin{array}{l}17 \\
(5)\end{array}$ & $\begin{array}{l}33.33 \\
(8)\end{array}$ & $\begin{array}{l}55 \\
(11)\end{array}$ & $\begin{array}{l}12.5 \\
\text { (1) }\end{array}$ & NT & $\begin{array}{l}20 \\
(1)\end{array}$ & NT \\
\hline
\end{tabular}


Ekeng et al.; ARRB, 36(6): 10-18, 2021; Article no.ARRB.69255

\begin{tabular}{|c|c|c|c|c|c|c|c|c|c|}
\hline Ant. & E. coli & $\begin{array}{l}\text { Providencia } \\
\text { spp. }\end{array}$ & K. spp & Proteus spp. & M. morganii & E. spp. & P. aeruginosa & C. freundii & A. spp. \\
\hline CFX & $\begin{array}{l}28.87 \\
(28)\end{array}$ & $\begin{array}{l}27.78 \\
(10)\end{array}$ & NT & $\begin{array}{l}25 \\
(6)\end{array}$ & $\begin{array}{l}55 \\
(11)\end{array}$ & $\begin{array}{l}36.3 \\
(4)\end{array}$ & NT & $\begin{array}{l}20 \\
(1)\end{array}$ & NT \\
\hline CTM & $\begin{array}{l}7.21 \\
(7)\end{array}$ & NT & NT & $\begin{array}{l}4.17 \\
(1)\end{array}$ & $\begin{array}{l}10 \\
(2)\end{array}$ & NT & NT & $\begin{array}{l}20 \\
(1)\end{array}$ & $\begin{array}{l}25 \\
(1)\end{array}$ \\
\hline PTZ & $\begin{array}{l}16.49 \\
(16)\end{array}$ & $\begin{array}{l}19.44 \\
(7)\end{array}$ & NT & $\begin{array}{l}16.67 \\
(4)\end{array}$ & $\begin{array}{l}40 \\
(8)\end{array}$ & $\begin{array}{l}12.5 \\
(1)\end{array}$ & $\begin{array}{l}36.3 \\
(4)\end{array}$ & $\begin{array}{l}40 \\
(2)\end{array}$ & $\begin{array}{l}25 \\
(1)\end{array}$ \\
\hline
\end{tabular}

CN, Gentamicin; AK, Amikacin; LEV, Levofloxacin; CIP, Ciprofloxacin; AMC, Amoxicillin Clavulanate; MEP, Meropenem; CFM, Cefepime; COX, Cefoxitin; IMP, Imipenem; CPD, Cefpodoxime; AMP, Ampicillin; CTZ, Ceftazidime; NIT, Nitrofurantoin; CFX, Cefixime; CTM, Cefotaxime; PTZ, Piperacillin Tazobactam; Ant. Antibiotics

\section{Table 4. Antibiotic resistance pattern of Gram-positive bacterial isolates}

\begin{tabular}{|c|c|c|c|c|}
\hline \multirow[t]{2}{*}{ Antibiotics } & S. aureus & CoNS & MRSA & Enterococcus spp. \\
\hline & \multicolumn{4}{|c|}{$\%(n)$} \\
\hline Gentamicin & $13.89(5)$ & $33.33(1)$ & $0 \%$ & $10.04(3)$ \\
\hline Amikacin & $2.78(1)$ & $33.33(1)$ & NT & NT \\
\hline Levofloxacin & $19.44(7)$ & $33.33(1)$ & $0 \%$ & $10.04(3)$ \\
\hline Ciprofloxacin & $13.87(5)$ & $0 \%(0)$ & $33.33(2)$ & $0(0)$ \\
\hline Erythromycin & $16.67(6)$ & $33.33(1)$ & NT & $21.74(5)$ \\
\hline Cefoxitin & $2.78(1)^{\prime}$ & NT & NT & NT \\
\hline Clindamycin & $0 \%(0)$ & NT & NT & NT \\
\hline Nitrofurantoin & $19.44(7)$ & $66.67(2)$ & $0 \%$ & $10.04(3)$ \\
\hline Penicillin & $2.78(1)$ & $33.33(1)$ & NT & NT \\
\hline Linezolid & NT & NT & NT & $17.39(4)$ \\
\hline Vancomycin & NT & NT & NT & $4.35(1)^{\prime}$ \\
\hline
\end{tabular}


Table 5. Frequency and Percentage of ESBL-producing isolates

\begin{tabular}{lll}
\hline Bacterial isolates & $\mathbf{N}$ & $\mathbf{\%}(\mathbf{n} / \mathbf{2 4})$ \\
\hline Escherichia coli & 16 & 66.67 \\
Pseudomonas aeruginosa & 2 & 8.33 \\
Providencia rettgeri & 1 & 4.17 \\
Klebsiella pneumoniae & 1 & 4.17 \\
Enterobacter cloacae & 2 & 8.33 \\
Citrobacter freundii & 2 & 8.33 \\
Total & 24 & 100 \\
\hline \multicolumn{1}{c}{ ESBL, extended-spectrum $\beta$-lactamase; $n$, number of ESBL isolates; \%, percentage of ESBL isolates }
\end{tabular}

Table 6. Frequency and percentage of multidrug resistant isolates

\begin{tabular}{lcl}
\hline Organisms & $\mathbf{N}$ & $\mathbf{\%}(\mathbf{n} / \mathbf{1 4 5})$ \\
\hline Escherichia coli & 50 & 34.48 \\
Staphylococcus spp. & 19 & 13.1 \\
Klebsiella spp. & 23 & 15.86 \\
Providencia spp. & 12 & 8.28 \\
Proteus spp. & 8 & 5.52 \\
Enterococcus spp. & 9 & 6.21 \\
Morganella morganii & 9 & 6.21 \\
Enterobacter spp. & 7 & 4.83 \\
Pseudomonas aeruginosa & 2 & 1.38 \\
Citrobacter freundii & 3 & 2.07 \\
Acinetobacter spp. & 3 & 2.07 \\
Total & 145 & 100 \\
\hline \multicolumn{2}{c}{$n$, number of Multidrug resistant isolates; \%, percentage of Multidrug resistant isolates }
\end{tabular}

ESBL producing strains were 24 and comprised $10.08 \%(24 / 238)$ of the Gram-negative group of organisms. The prevalence of ESBL in our study was lower compared to a prevalence of $32.7 \%$ in a study done by Onwuezobe et. al, in a tertiary hospital, in Uyo, Nigeria [22]. Of the 24 ESBL producing strains, $E$. coli had the largest proportion $(n=16)$, as shown in Table 5.

The production of ESBL by Gram negative organisms confers resistance to beta-lactam antibiotics through the hydrolyzation of the betalactam ring in beta-lactam drugs including penicillins, cephalosporins, and aztreonam, except cephamycins and carbapenems, and are usually associated with poor outcome of infections [1]. ESBL genes are encoded by plasmids which have been found to carry other genes that express resistance to drugs other than beta-lactams, such as aminoglycosides, trimethoprim, sulphonamides, tetracyclines, quinolones and chloramphenicol and as such have been implicated as a major cause of multidrug resistance $[1,23,24]$.

The increasing rates of antimicrobial resistance of pathogenic organisms has become a public health problem. There is a startling increase in antibiotic resistance of bacteria that cause either nosocomial infections or community acquired infections. Worthy of note are the multidrug resistant pathogens like Klebsiella pneumoniae, Escherichia coli, Acinetobacter Baumannii and methicillin-resistant Staphylococcus aureus [18]. Our study revealed a multi drug resistance rate of $47.39 \%(145 / 306)$ amongst bacterial isolates. Of the 145 multi drug resistant isolates, $E$. coli had the highest frequency $(n=50)$, with a prevalence of $34.48 \%(50 / 145)$, Table 6 . This was slightly higher than a prevalence rate of $27.3 \%$ from a study done by Maduakor et al in a tertiary hospital, in Enugu, Nigeria [25]. Higher prevalence rates of multi drug resistant $E$. coli $(52.9 \%)$ have also been reported from other studies [26].

\section{CONCLUSION}

The spectrum of uropathogens and their antibiotic susceptibility continue to change and vary globally. The predominance of $E$. coli in our study was a finding consistent with many previous reports. Culture isolates showed high resistance to routinely used antibiotics except the carbapenems. The high resistance rates to antibiotics can be explained by the over use and 
the non-judicious use of antibiotics for the treatment of UTI. The availability of these drugs over the counter without a physician's prescription has also encouraged the inappropriate use of antibiotics. Urine culture and antibiotic sensitivity testing should be done for all patients with suspected UTI especially where local antibiograms are not available.

\section{LIMITATIONS OF THE STUDY}

- The study was unable to state the type of UTI (uncomplicated or complicated) and associated comorbidities which may have direct implication on the cause and management of UTI due to paucity and lack of detailed clinical information from extracted records.

- The Study could not differentiate between patients from the outpatient department and patients from the inpatient department due to similar reasons stated above.

\section{COMPETING INTERESTS}

Authors have declared that no competing interests exist.

\section{REFERENCES}

1. Kumar A, Kumar R, Gari M, Keshri UP, Mahato SK, Ranjeeta K. Antimicrobial susceptibility pattern of urine culture isolates in a tertiary care hospital of Jharkhand, India. IJBCP. 2017;6(7):1733.

2. Bilchenko AV, Chub OI. Prevalence of types TEM, SHV and CTX-M _LES among pathogens of chronic pyelonephritis. Antibiot. Khimioter. 2014;59(11-12):24-26.

3. Medina M, Castillo-Pino E. An introduction to the epidemiology and burden of urinary tract infections. Therapeutic Advances in Urology. 2019;11:3-7.

4. Badri AM, Mohamed SG. Clinical epidemiology and antibiogram of UTI patients attended different hospital in Khartoum, Sudan. Clin Microbiol. 2017;6: 301.

5. Tille, PM. Bailey and scott's diagnostic microbiology, $13^{\text {th }}$ edition, St. Louis, Missouri: Elsevier; 2014.

6. Iqbal $\mathrm{R}$, Ikram $\mathrm{N}$, Shoaib $\mathrm{M}$, Asad MJ, Mehmood RT, Niazi A, et al. Phenotypic confirmatory disc diffusion test (PCDDT), double disc synergy test (DDST), E-test OS diagnostic tool for detection of extended spectrum beta lactamase (ESBL) producing Uropathogens. J Appl Biotechnol Bioeng. 2017;3(3):344-349.

7. Weinstein MP, Patel JB, Bobenchik AM, Campeau S, Cullen SK, Gallas MF, et. al. Clinical and laboratory standard institute. Performance Standards for Antimicrobial Susceptibility Testing. 29th ed. Wayne, PA; 2019.

8. Jombo GTA, Emanghe UE, Amefule EN, Damen JG. Urinary tract infections at a Nigerian university hospital: Causes, patterns and antimicrobial susceptibility profile. J. Microbiol. Antimicrob. 2011;3(6): 153-159.

9. Tandogdu Z, Wagenlehner FME. Global epidemiology of urinary tract infections. Curr. Opin. Infect. Dis. 2016;29(1):73-9.

10. World Health Organisation. Global priority list of antibiotic-resistant bacteria to guide research, discovery, and development of new antibiotics. WHO: Geneva, Switzerland. 2017;7.

11. Marami D, Balakrishnan S, Seyoum B. Prevalence, antimicrobial susceptibility pattern of bacterial isolates and associated factors of urinary tract infections among HIV-positive patients at Hiwot Fana specialized university hospital. Eastern Ethiopia. CJID. 2019;8.

12. Iregbu KC, Nwajiobi-Princewill PI. Urinary tract infections in a tertiary hospital in Abuja, Nigeria. Afr.J. Cln. Exper. Microbiol. 2013;14(3):169-173.

13. Foxman B. Epidemiology of urinary tract infections: incidence, morbidity, and economic costs. Dis Mon. 2003;49(2):5370.

14. Dielubanza EJ, Schaeffer AJ. Urinary tract infections in women. Med Clin North Am. 2011;95(1):27-41.

15. Uwingabiye $J$, Frikh $M$, Lemnouer $A$, Bssaibis $F$, Belefquih $B$, Maleb $A$, et. al. Acinetobacter infections prevalence and frequency of the antibiotics resistance: comparative study of intensive care units versus other hospital units. Pan Afr Med J. 2016;23:191.

16. Khan FY, Eldeeb $\mathrm{Y}$, Almaslamani $\mathrm{M}$, Alkhal $A$, Alsoub $H$, Ghadban $W$, et. al. Acinetobacter Infections among adult patients in Qatar: A 2-year hospital-based study. CJID; 2016.

17. Alo MN, Saidu AY, Ugah UI, Alhassan M. Prevalence and antbiogram of bacterial isolates causing urinary tract infections at federal teaching hospital abakaliki (FETHA). BMRJ. 2015;8(2):403-417. 
18. Santajit S, Indrawattana N. Mechanisms of antimicrobial resistance in ESKAPE pathogens. BioMed Res. Int. 2016; Article ID 2475067, 8 pages.

19. Odoki M, Aliero AA, Tibyangye J, et al. Prevalence of bacterial urinary tract infections and associated factors among patients attending hospitals in Bushenyi District, Uganda. Int. J. Microbiol. 2019;8.

20. Bouza E, San Juan R, Mun oz P, Voss A, Kluytmans J. A European perspective on nosocomial urinary tract infections I. Report on the microbiology workload, aetiology and antimicrobial susceptibility (ESGNI-003 study). Clin. Microbiol. Infect. 2001;7(10).

21. Oladeinde $B H$, Omoregie $R$, Olley $M$, Anunibe JA. Urinary tract infection in a rural community of Nigeria. N. Am. J. Med. Sci. 2011;3(2):75-77.
22. Onwuezobe IA, Etang UE. Current antibiotic resistance trends of uropathogens from outpatients in a Nigerian urban health care facility. IJHMS. 2018;4(6):99-104.

23. Rawat D, Nair D. Extended-spectrum $\beta$ lactamases in gram negative bacteria. J Glob Infect Dis. 2010;2(3):263-74.

24. Paterson DL, Bonomo RA. Clin. Microbiol. Rev. 2005;18(4):657-686.

25. Maduakor U, Ugwu UL, Azubuike N, et al. Uropathogens and antimicrobial susceptibility pattern in adult patients attending a tertiary hospital in Enugu, Nigeria. Int. J. Infect. Dis. 2019;17(1).

26. Hasan AS, Nair D, Kaur J, Baweja G, Deb $M$, Aggarwal P. Resistance patterns of urinary isolates in a tertiary Indian hospital. J Ayub Med Coll Abbottabad. 2007;19(1): 39-41.

(c) 2021 Ekeng et al.; This is an Open Access article distributed under the terms of the Creative Commons Attribution License (http://creativecommons.org/licenses/by/4.0), which permits unrestricted use, distribution, and reproduction in any medium, provided the original work is properly cited.

Peer-review history:

The peer review history for this paper can be accessed here: http://www. sdiarticle4.com/review-history/69255 